\title{
Structure of a major glycolipid from Thermus oshimai NTU-063
}

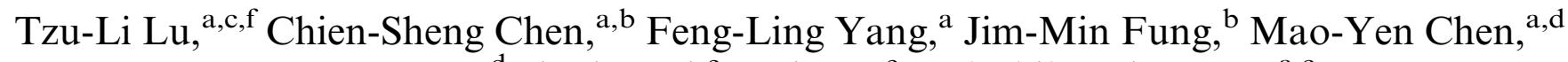 \\ San-San Tsay, ${ }^{\mathrm{d}}$ Jianjun $\mathrm{Li}^{\mathrm{e}}{ }^{\mathrm{e}}$ Wei $\mathrm{Zou}^{\mathrm{e}}$ and Shih-Hsiung $\mathrm{Wu}^{\mathrm{a}, \mathrm{c}, *}$ \\ ${ }^{a}$ Institute of Biological Chemistry, Academia Sinica, Taipei 115, Taiwan \\ ${ }^{\mathrm{b}}$ Department of Chemistry, National Taiwan University, Taipei 106, Taiwan \\ ${ }^{\mathrm{c}}$ Institute of Biochemical Sciences, National Taiwan University, Taipei 106, Taiwan \\ ${ }^{\mathrm{d}}$ Department of Life Science and Institute of Plant Biology, National Taiwan University, Taipei 106, Taiwan \\ ${ }^{\mathrm{e}}$ Institute for Biological Sciences, National Research Council of Canada, Ottawa, Ontario, Canada \\ ${ }^{\mathrm{f}}$ School of Medical Laboratory Science and Biotechnology, China Medical University, Taichung, Taiwan
}

Received 29 May 2004; received in revised form 10 August 2004; accepted 10 August 2004

Available online 17 September 2004

\begin{abstract}
The structure of a major glycolipid isolated from the thermophilic bacteria Thermus oshimai NTU-063 was elucidated. The sugar and fatty acid compositions were determined by GC-MS and HPLC analysis on their methanolysis and methylation derivatives, respectively. After removal of both $O$ - and $N$-acyl groups by alkaline treatment, the glycolipid was converted to a fully acetylated tetraglycosyl glycerol derivative, the structure of which was then determined by NMR spectroscopy (TOCSY, HSQC, HMBC). Thus, the complete structure of the major glycolipid from $T$. oshimai NTU-063 was established as $\beta-G l c p-(1 \rightarrow 6)-\beta-$ Glc $p$ - $(1 \rightarrow 6)$ - $\beta$-Glc $p$ NAcyl- $(1 \rightarrow 2)-\alpha$-Glc $p$ - $(1 \rightarrow 1)$-glycerol diester. The $N$-acyl groups on the 2-amino-2-deoxy-glucopyranose residue are $\mathrm{C}_{15: 0}$ and $\mathrm{C}_{17: 0}$ fatty acids, whereas the fatty acids of glycerol diester are more heterogeneous including both straight and branched fatty acids from $\mathrm{C}_{15: 0}$ to $\mathrm{C}_{18: 0}$.

(C) 2004 Elsevier Ltd. All rights reserved.
\end{abstract}

Keywords: Thermus oshimai; Thermophilic bacteria; Polar glycolipid; NMR; Mass spectroscopy

\section{Introduction}

Thermophilic bacteria are able to grow in extreme conditions because of their unique membrane structure. ${ }^{1-4}$ Novel lipids identified include alkylglycerol diethers (1,2-di-O-alkylglycerols) from Aquifex pyrophilus ${ }^{5}$ and Thermodesulfotobacterium commune, ${ }^{6} \alpha, \omega$-dicarboxylic fatty acids from Thermotogales ${ }^{7}$ and long-chain 1,2diols from $T$. scotoductus and Thermomicrobium roseum. ${ }^{8}$ A high proportion of polar lipids found in thermophilic eubacteria, for example, T. aquaticus, T. filiformis, T. scotoductus, and T. oshimai are also believed to be critical for thermal stability. ${ }^{9-11}$ Among

\footnotetext{
*Corresponding author. Fax: +886 22653 9142; e-mail: shwu@ gate.sinica.edu.tw
}

them, phospholipids and glycolipids are two major ones, and most glycolipids from Thermus species examined thus far contain three hexoses, one $N$-hexosamine, and one glycerol. ${ }^{9-11}$ In addition, the sequence of the carbohydrate moiety has been studied by chemical and mass spectroscopic analyses. However, complete structure information, particularly the linkages and configurations of the carbohydrate moiety, is still lacking. In this study, we elucidated the full structure of a major glycolipid isolated from T. oshimai NTU-063 in Taiwan. The fatty acids were determined by MS analysis on native and de- $O$-acylated glycolipids as well as by $\mathrm{GC}-$ MS analysis on their methyl esters. A fully acetylated tetraglycosyl glycerol was used for linkage and configuration studies by NMR spectroscopy. Structural analysis of these compounds may facilitate the understanding of the biosynthesis of these glycolipids in bacteria. 


\section{Experimental}

\subsection{Analytical methods}

GC-MS was carried out on a Hewlett Packard Gas Chromatography HP6890 connected to an HP5973 Mass Selective Detector. A HP-5MS fused silica capillary column $(30 \mathrm{~m} \times 0.25 \mathrm{~mm}$ I.D., HP $)$ at $60^{\circ} \mathrm{C}$ was used. The program for analyses of TMS and FAMEs (fatty acid methyl esters) derivatives was set up at $60^{\circ} \mathrm{C}$ for $1 \mathrm{~min}$, increasing to $140^{\circ} \mathrm{C}$ at $25^{\circ} \mathrm{C} / \mathrm{min}$, to $200^{\circ} \mathrm{C}$ at $5^{\circ} \mathrm{C} / \mathrm{min}$, and finally to $300^{\circ} \mathrm{C}$ at $10^{\circ} \mathrm{C} / \mathrm{min}$. For PMAAs (partial methylated aditol acetates) derivatives, the oven was programmed at $60^{\circ} \mathrm{C}$ for $1 \mathrm{~min}$ before increasing to $290^{\circ} \mathrm{C}$ at $8^{\circ} \mathrm{C} / \mathrm{min}$, and finally to $300^{\circ} \mathrm{C}$ at a rate of $10^{\circ} \mathrm{C} / \mathrm{min}$. Peaks were analyzed by GC-MS and compared with the Complex Carbohydrate Research Center's PMAA database (www.ccrc.uga.edu/ web/specdb/ms/pmaa/pframe.html). An arabitol derivative was used as the internal standard.

HPAEC-PAD (high performance anion exchange chromatography with pulsed amperometric detection) analysis was used to determine the sugar composition. The hydrolysates from the $N$-acetyl glycosyl glycerol were analyzed by HPAEC-PAD in a DX-500 BioLC system, which included a GP40 gradient pump, an ED40 electrochemical detector (PAD detection) with a working gold electrode, a LC30 column oven, and an AS3500 autosampler. The Dionex Eluant Degas Module was employed to purge and pressurize the eluants with helium. The monosaccharides were separated on Carbopac PA10 analytical column $(4 \times 250 \mathrm{~mm})$ with Carbopac PA10 Guard $(4 \times 50 \mathrm{~mm})$ column, flowing at a rate of $1 \mathrm{~mL} / \mathrm{min}$ at $30^{\circ} \mathrm{C}$, and detected by the following pulse potentials and durations: $E_{1}=0.05 \mathrm{~V} \quad(0.4 \mathrm{~ms}) ; \quad E_{2}=0.75 \mathrm{~V}$ $(0.2 \mathrm{~ms})$; and $E_{3}=-0.15 \mathrm{~V}(0.4 \mathrm{~ms})$. The integration was recorded from 0.2 to $0.4 \mathrm{~ms}$ during the $E_{1}$ application.

\subsection{Organism and growth condition}

The Thermus oshimai NTU-063 isolate was obtained from Wu-rai hot springs, Taiwan. All biochemical tests and identification procedures were performed as specified previously. ${ }^{12,13}$ After extraction of genomic DNA, PCR-mediated amplification, and sequencing of the purified PCR product, the 16S rDNA sequence was compared with the previously determined Thermus sequences available from the EMBL database. T. oshimai NTU-063 was cultivated with optimum growth temperature at $65^{\circ} \mathrm{C}$ in a liquid Thermus modified medium and harvested until the late exponential phase $\left(\mathrm{OD}_{600}=1.4-1.5\right)$.

\subsection{Isolation of glycolipids}

A suspension of wet bacteria in absolute ethanol (w/ $\mathrm{v}=1 / 10, \mathrm{RDH})$ was shaken at room temperature for
$2 \mathrm{~h}$. After centrifugation, the supernatant was collected, lyophilized, and purified through a silica gel G-60 column (Merck) eluted with gradient of chloroform/methanol from 20:1 to 3:1. The carbohydrate-containing fractions were detected by TLC (stained with $0.02 \mathrm{M}$ ammonium cerium sulfate dihydrate and ammonium molybdate tetrahydrate in aqueous $10 \% \mathrm{H}_{2} \mathrm{SO}_{4}$ ) and collected. The glycolipids were heterogeneous according to the MS analysis due to the variations in fatty acids, and soluble in neither water nor chloroform.

\subsection{Chemical modification}

De-O-acylation: Glycolipids from the ethanol extraction were treated with $1 \% \mathrm{NaOCH}_{3} / \mathrm{CH}_{3} \mathrm{OH}$ at room temperature for $5 \mathrm{~h}$. The mixture was neutralized by the addition of Dowex $50\left(\mathrm{H}^{+}\right)$resin and the filtrate was concentrated. Purification was performed by silica gel G-60 chromatography $\left(\mathrm{CH}_{3} \mathrm{OH} / \mathrm{CHCl}_{3} \quad 1: 3\right)$ and gave the de- $O$-acylated glycolipids.

Per-acetylated glycosylglycerol: The glycolipids were treated with $2 \mathrm{~N} \mathrm{NaOH}$ at $100^{\circ} \mathrm{C}$ for $8 \mathrm{~h}$ to remove both $O$ - and $N$-acyl groups. The mixture was then neutralized by acetic anhydride, which resulted in partial re- $N$ acetylation. The precipitate was removed by centrifugation and the supernatant containing the sugar was collected and lyophilized. A fully acetylated sample was then obtained by treatment of the previous sample with $\mathrm{Ac}_{2} \mathrm{O} /$ pyridine (1:2) for $3 \mathrm{~h}$. The reaction was quenched by the addition of $\mathrm{CH}_{3} \mathrm{OH}(1 \mathrm{~mL})$. The final mixture was concentrated to a residue, which was purified on silica gel G-60 chromatography (EtOAc/hexanes 2:1) to give the per-acetylated glycosylglycerol derivative.

$\mathrm{N}$-acetyl-glycosylglycerol: De- $\mathrm{O}$-acetylation was performed by treatment of the per-acetylated glycosylglycerol with $0.01 \mathrm{M} \mathrm{NaOCH}_{3}$ at room temperature for $3 \mathrm{~h}$. The solution was neutralized by the addition of Dowex $50\left(\mathrm{H}^{+}\right)$resin, concentrated, and lyophilized to give the $N$-acetylated glycosylglycerol.

\subsection{Composition analysis}

Fatty acid composition was determined by comparing the retention times of FAMEs from glycolipids to the standards in GC-MS analysis. The methyl esters were prepared by treatment of the glycolipids with $0.5 \mathrm{M}$ $\mathrm{HCl}-\mathrm{CH}_{3} \mathrm{OH}$ at $80^{\circ} \mathrm{C}$ for $1 \mathrm{~h}$. The solvent was removed under a nitrogen stream and the residue was partitioned between $\mathrm{CHCl}_{3}$ and $\mathrm{H}_{2} \mathrm{O}$. FAMEs in the organic phase were analyzed by GC-MS.

For sugar composition analysis, the $N$-acetylated glycosylglycerol was subjected to acidic hydrolysis (2 M TFA at $100^{\circ} \mathrm{C}$ for $5 \mathrm{~h}$ ) to release the monosaccharides, which were further analyzed by HPAEC-PAD. Hakomori methylation analysis ${ }^{14,15}$ was used for determination of sugar composition and linkages. 
Table 1. Fatty acids present in a major glycolipid from Thermus oshimai NTU-063

\begin{tabular}{lc}
\hline Fatty acid & Composition $(\%)$ \\
\hline Straight chain & \\
16:0 & 2.2 \\
18:0 0 & 2.5 \\
Anteisobranched & \\
15:0 & 11.4 \\
17:0 & 9.5 \\
Isobranched & \\
15:0 & 36.6 \\
$16: 0$ & 7.6 \\
$17: 0$ & 30.1 \\
\hline
\end{tabular}

\subsection{NMR analysis}

A sample of the per-acetylated glycosylglycerol $(1.0 \mathrm{mg})$ in $\mathrm{CDCl}_{3}(0.6 \mathrm{~mL})$ was used for determination of the carbohydrate configuration, linkages, and sequences using NMR spectroscopy. NMR spectra were recorded with a Bruker AVANCE-500 spectrometer equipped with a CryoProbe ${ }^{16}$ at $300 \mathrm{~K}$ using the XwIN-NMR 3.5 software. ${ }^{1} \mathrm{H}$ and ${ }^{13} \mathrm{C}$ chemical shifts are given in ppm relative to internal TMS (0ppm) and $\mathrm{CDCl}_{3}(77 \mathrm{ppm})$, respectively. All 2-D NMR experiments were carried out with standard pulse sequences provided by Bruker. 1D-TOCSY spectra were recorded with mixing times $(200,160,120$, and $80 \mathrm{~ms})$ that allowed the assignments of the proton resonances of Glc $p$ and Glc $p$ NAc from H1 to H-6. The NMR data were processed on a personal computer (Windows Professional 2000, Microsoft) using XWIN-NMR 3.1 and AURELIA 3.1 software packages (Karlsruhe, Germany). FIDs were multiplied by skewed phase-shifted sine bell window functions prior to further transformation. Data were zero filled to 1024 data points in both dimensions. Cross peaks taken along the $\omega_{2}$-axis were subjected to an inverse Fourier transformation zero-filled to 8092 data points and Fourier transformed to give a digital resolution of $0.8 \mathrm{~Hz} /$ point.
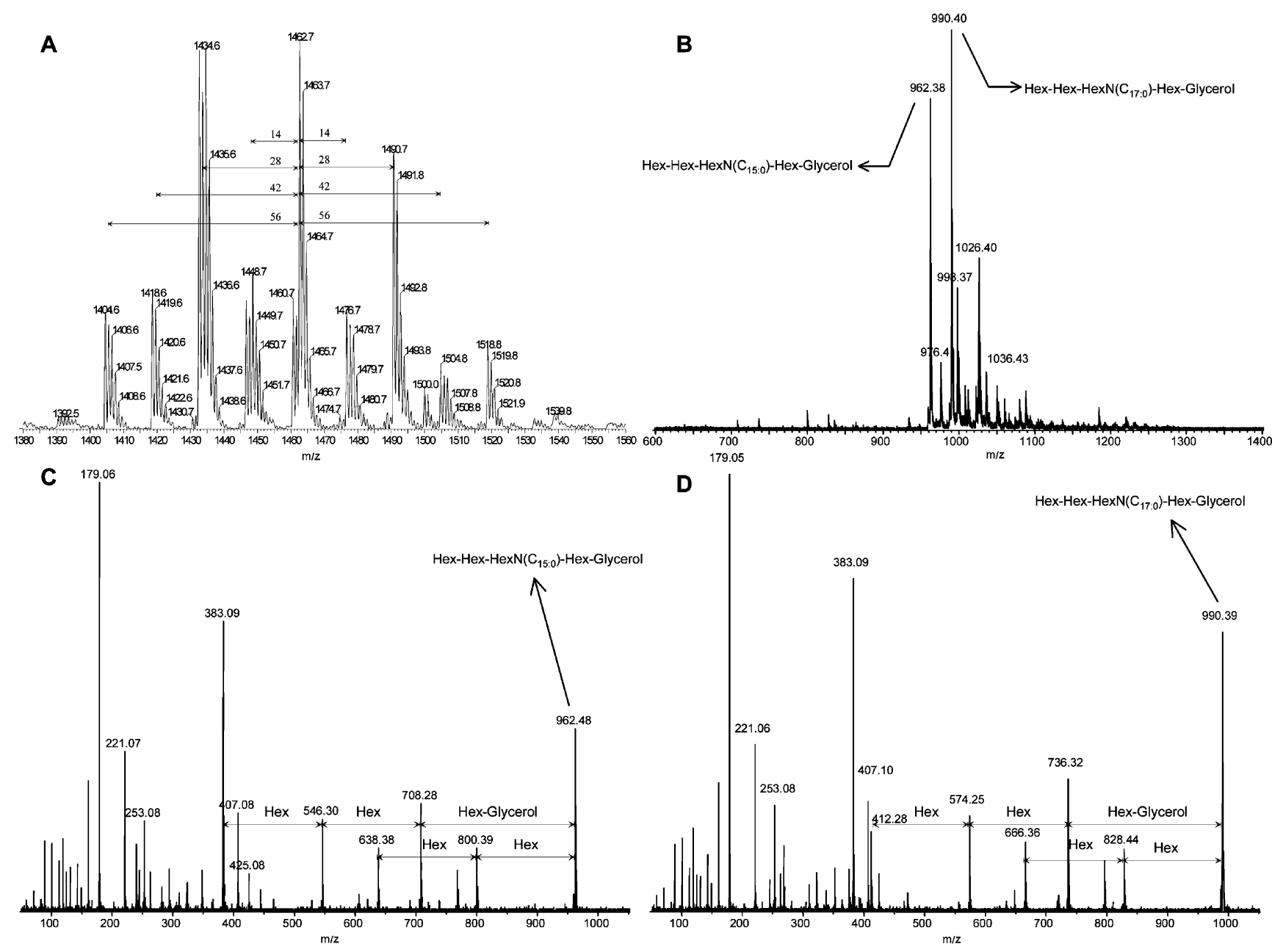

Figure 1. Mass spectra of the native glycolipids and de- $O$-acetylated glycolipids. (A) MALDI-TOF mass spectra (+ev) of native glycolipids in Thermus oshimai NTU-063. Each finger-printing area resulted in a difference of 14 owing to a $\mathrm{CH}_{2}$ group of fatty acid chain; the peak at $m / z 1462$ $\left(\mathrm{M}+\mathrm{Na}^{+}\right)$represents a glycolipid with three glucopyranose, one 2-amino-2-deoxy-glucopyranose, one glycerol, and three fatty acids (one $\mathrm{C}_{17: 0}$ and two $\mathrm{C}_{15: 0}$ ). (B) ES-MS (-ev) spectra of the de- $O$-acetylated glycolipids. The difference of the molecular mass between peaks at $\mathrm{m} / z 962$ and 990 indicates the $N$-acyl group linked to glycosamine is either $\mathrm{C}_{15: 0}$ or $\mathrm{C}_{17: 0}$ as confirmed by MS/MS analysis (C and D). 


\section{Results and discussion}

The fatty acid composition of the major glycolipid isolated from $T$. oshimai NTU-063 was obtained by GC-MS analysis on FAMEs derived from glycolipid by methanolysis in $0.5 \mathrm{M} \mathrm{HCl}-\mathrm{CH}_{3} \mathrm{OH}$. Quantitative analysis indicated that the fatty acids were mainly isobranched $\mathrm{C}_{15: 0}$ to $\mathrm{C}_{17: 0}(74 \%)$ and anteisobranched $\mathrm{C}_{15: 0}$ and $\mathrm{C}_{17: 0}(21 \%)$. The remaining $5 \%$ of the fatty acids were straight chain $\mathrm{C}_{16: 0}$ and $\mathrm{C}_{18: 0}$ (Table 1).

Compositional analysis of sugars was independently performed using two methods. One was based on HPAEC-PAD analysis on the acid hydrolyzates of the $\mathrm{N}$-acetyl glycosylglycerol, which indicated that glucose, 2-amino-2-deoxy-glucose and glycerol were present in a ratio of 3:1:1. The other followed a standard methanolysis/TMS derivatization method, with the methylated sugar alditol acetates being analyzed by GC-MS and determined by comparison with authentic standards. The retention times were $13.92 / 14.06 \mathrm{~min}, 16.22 /$ $16.55 \mathrm{~min}$, and $19.36 \mathrm{~min}$ for glycerol, glucopyranose, and 2-amino-2-deoxy-glucopyranose derivatives, respectively. This analysis revealed that the glycolipid contains one terminal glucopyranose residue, one $1 \rightarrow 6$-linked glucopyranose residue, one $1 \rightarrow 6$ linked-2-amino-2deoxy-glucopyranose residue, one $1 \rightarrow 2$-linked glucopyranose residue, and one 1-linked glycerol moiety.

MALDI-TOF-MS analysis on the native glycolipids isolated from Thermus oshimai NTU-063 showed major peaks at $m / z$ (+ev) 1434, 1462, and 1490 (see Fig. 1A) and minor peaks with a difference $m / z 14$, indicating that the glycolipid was heterogeneous as expected due to the different lengths of the aliphatic chains on both glycerol and 2-amino-2-deoxy-glucopyranose residues. The main peak $m / z 1462\left(\mathrm{M}+\mathrm{Na}^{+}\right)$represents a glycolipid containing three glucopyranose residues, one 2-amino-2-deoxyglucopyranose residue, one glycerol moiety, and three fatty acids (one $\mathrm{C}_{17: 0}$ and two $\mathrm{C}_{15: 0}$ ). Meanwhile, ESMS analysis on the de- $O$-acylated glycolipids showed two major peaks at $\mathrm{m} / \mathrm{z}$ (-ev) 990 and 962 (Fig. 1B), suggesting the 2-amino-2-deoxy-glucopyranose residue was $N$-acylated with $\mathrm{C}_{15: 0}$ and $\mathrm{C}_{17: 0}$ (Fig. $1 \mathrm{C}$ and D). The ratio of $\mathrm{C}_{15: 0}: \mathrm{C}_{17: 0}$ was estimated to be approximately 1:1.2 based on the relative intensity of those two peaks ( $\mathrm{m} / \mathrm{z} 962$ vs 990$)$.

The fatty acid composition in T. oshimai NTU-063 is similar to most glycolipids from the genus Thermus. However, hydroxylated fatty acids, which are present in significant quantities (approximately 25-28\%) in glycolipids isolated from $T$. filiformis and T. aquaticus, were absent in this glycolipid. Small amounts of 3-hydroxylated $\mathrm{C}_{15: 0}$ and $\mathrm{C}_{17: 0}(<1 \%)$ was found in glycolipid GL1 from T. oshimai SPS-11. Besides this minor difference in 3-hydroxy fatty acid composition, the sugar composition of the major glycolipid from T. oshimai NTU-063 is the same as that of GL-1 from T. oshimai SPS-11.
The poor solubility and heterogeneity of the glycolipids makes analysis of the native glycolipids by NMR spectroscopy difficult. Thus, to improve solubility and homogeneity for NMR analysis, per-acetylated glycolipids were obtained by first the complete removal of fatty acids with strong base $(2 \mathrm{~N} \mathrm{NaOH})$ and then by acetylation in pyridine- $\mathrm{Ac}_{2} \mathrm{O}$. The ${ }^{1} \mathrm{H}$ NMR spectrum of the per-acetylated glycosylglycerol showed the amide proton at $\delta 6.31, N$-acetyl group at $\delta 1.92$, and $O$-acetyl groups at $\delta 2.01-2.17$, but the anomeric protons were not sufficiently resolved. However, we were able to assign the chemical shifts (Table 2) of all sugar protons by selective 1D TOCSY experiments (Fig. 2) with mixing times from 80 to $200 \mathrm{~ms}$; these analyses also allowed us to obtain information on the coupling constants. We identified the signals of four anomeric protons, terminal $\beta$-Glc $p$ at $\delta 4.59\left(J_{1,2} 7.8 \mathrm{~Hz}\right), \beta-(1 \rightarrow 6)-\mathrm{Glc} p$ at $4.49 \mathrm{ppm}$ $\left(J_{1,2} \quad 8.0 \mathrm{~Hz}\right), \quad \beta-(1 \rightarrow 2)-\mathrm{Glc} p \mathrm{NAc}$ at $5.04 \mathrm{ppm} \quad\left(J_{1,2}\right.$ $8.3 \mathrm{~Hz})$, and nonreducing end $\alpha-(1 \rightarrow 1)-$ Glep at $5.15 \mathrm{ppm}\left(J_{1,2} 4.1 \mathrm{~Hz}\right)$ as well as one 1 -glycerol moiety. The inter-residue glycosidic linkages were determined through a combination of HMBC and HSQC (Fig. 3) ${ }^{17,18}$ Based on the HMBC corrections (see Table 3 ), the terminal Glcp residue (A) was $\beta$-linked to O-6 of

Table 2. ${ }^{1} \mathrm{H}$ and ${ }^{13} \mathrm{C}$ chemical shifts of the acetylated tetraglycosyl glycerol derivative obtained from a major $T$. oshimai NTU-063 glycolipid

\begin{tabular}{|c|c|c|c|}
\hline Residue & Atom & $\delta_{\mathrm{H}}{ }^{\mathrm{a}}$ & $\delta_{\mathrm{C}}{ }^{\mathrm{a}}$ \\
\hline A & 1 & 4.59 & 101.4 \\
\hline \multirow[t]{5}{*}{$\beta$-Glc $p(1 \rightarrow\}$} & 2 & 5.05 & 70.9 \\
\hline & 3 & 5.26 & 72.1 \\
\hline & 4 & 5.08 & 68.5 \\
\hline & 5 & 3.79 & 72.3 \\
\hline & 6 & $4.30,4.14$ & 62.1 \\
\hline $\mathrm{B}$ & 1 & 4.49 & 101.0 \\
\hline \multirow{5}{*}{ 6)- $\beta$-Glc $p(1 \rightarrow\}$} & 2 & 4.93 & 70.9 \\
\hline & 3 & 5.18 & 72.5 \\
\hline & 4 & 4.86 & 69.5 \\
\hline & 5 & 3.76 & 69.3 \\
\hline & 6 & 3.79 & 69.1 \\
\hline $\mathrm{C}$ & 1 & 5.04 & 98.6 \\
\hline \multirow[t]{6}{*}{ 6)- $\beta$-Glc $p$ NAcc $(1 \rightarrow\}$} & 2 & 3.44 & 55.8 \\
\hline & 3 & 5.56 & 71.4 \\
\hline & 4 & 4.86 & 69.5 \\
\hline & 5 & 3.88 & 72.3 \\
\hline & 6 & 3.73 & 69.0 \\
\hline & $\mathrm{Nac}$ & 1.27 & 29.7 \\
\hline $\mathrm{D}$ & 1 & 5.15 & 99.9 \\
\hline \multirow[t]{5}{*}{ 2)- $\alpha$-Glc $p(1 \rightarrow\}$} & 2 & 3.74 & 76.2 \\
\hline & 3 & 5.39 & 71.3 \\
\hline & 4 & 4.96 & 68.8 \\
\hline & 5 & 4.05 & 67.2 \\
\hline & 6 & $4.30,4.08$ & 62.2 \\
\hline $\mathrm{E}$ & 1 & $3.89,3.79$ & 67.2 \\
\hline \multirow[t]{2}{*}{ 1)-Glycerol } & 2 & 5.28 & 69.8 \\
\hline & 3 & $4.41,4.33$ & 62.9 \\
\hline
\end{tabular}

a In ppm; measured from the HSQC spectrum obtained at $500 \mathrm{MHz}$ in $\mathrm{CDCl}_{3}(\delta 7.24 \mathrm{ppm})$ at $300 \mathrm{~K}$. 


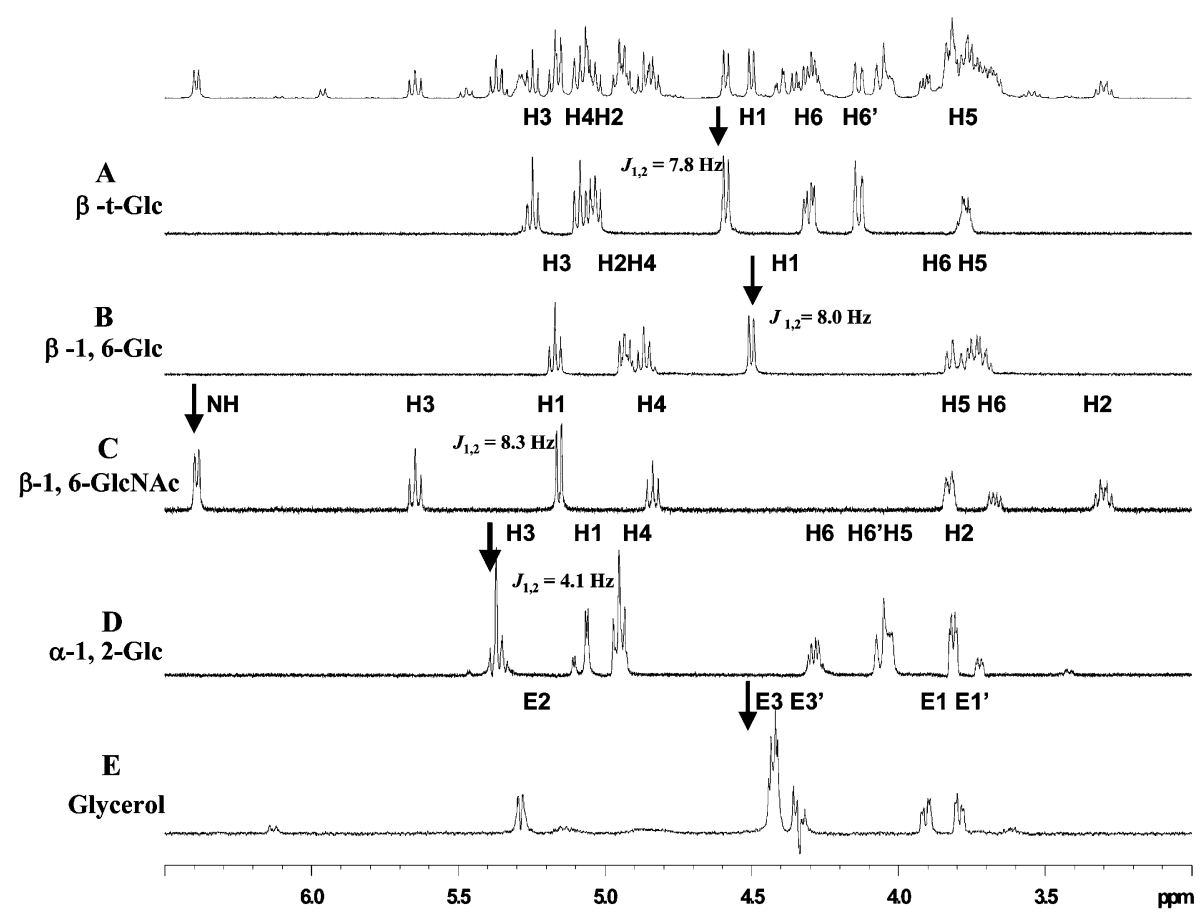

Figure 2. The $500 \mathrm{MHz}^{1} \mathrm{H}$ NMR spectrum and $1 \mathrm{D}$ TOCSY $\left(\mathrm{CDCl}_{3}\right.$, at $\left.300 \mathrm{~K}\right)$ of acetylated tetraglycosylglycerol. Anomeric protons of the terminal $\beta$-Glc $p$ and $\beta-1 \rightarrow 6$-Glc $p$ residues, amide proton of $\beta-1 \rightarrow 6-$ Glc $p$ NAc residue, and H-3 of $\alpha-1 \rightarrow 2$-Glc $p$ residue are irradiated in respective 1D TOCSY experiments. Chemical shifts of the anomeric protons are assigned as follows: terminal $\beta$-Glc $p$ residue at $\delta 4.59\left(J_{1,2} 7.8 \mathrm{~Hz}\right), \beta-1 \rightarrow 6-\mathrm{Glc} p$ residue at $4.49\left(J_{1,2} 8.0 \mathrm{~Hz}\right), \beta-1 \rightarrow 6-\mathrm{Glc} p$ NAc residue at $5.04\left(J_{1,2} 8.3 \mathrm{~Hz}\right)$, and the $\alpha-1 \rightarrow 2$-Glc $p$ residue at $5.15\left(J_{1,2} 4.1 \mathrm{~Hz}\right)$ ppm. The proton signals for each residue were confirmed by $2 \mathrm{D}-{ }^{1} \mathrm{H}-{ }^{1} \mathrm{H}$ COSY.

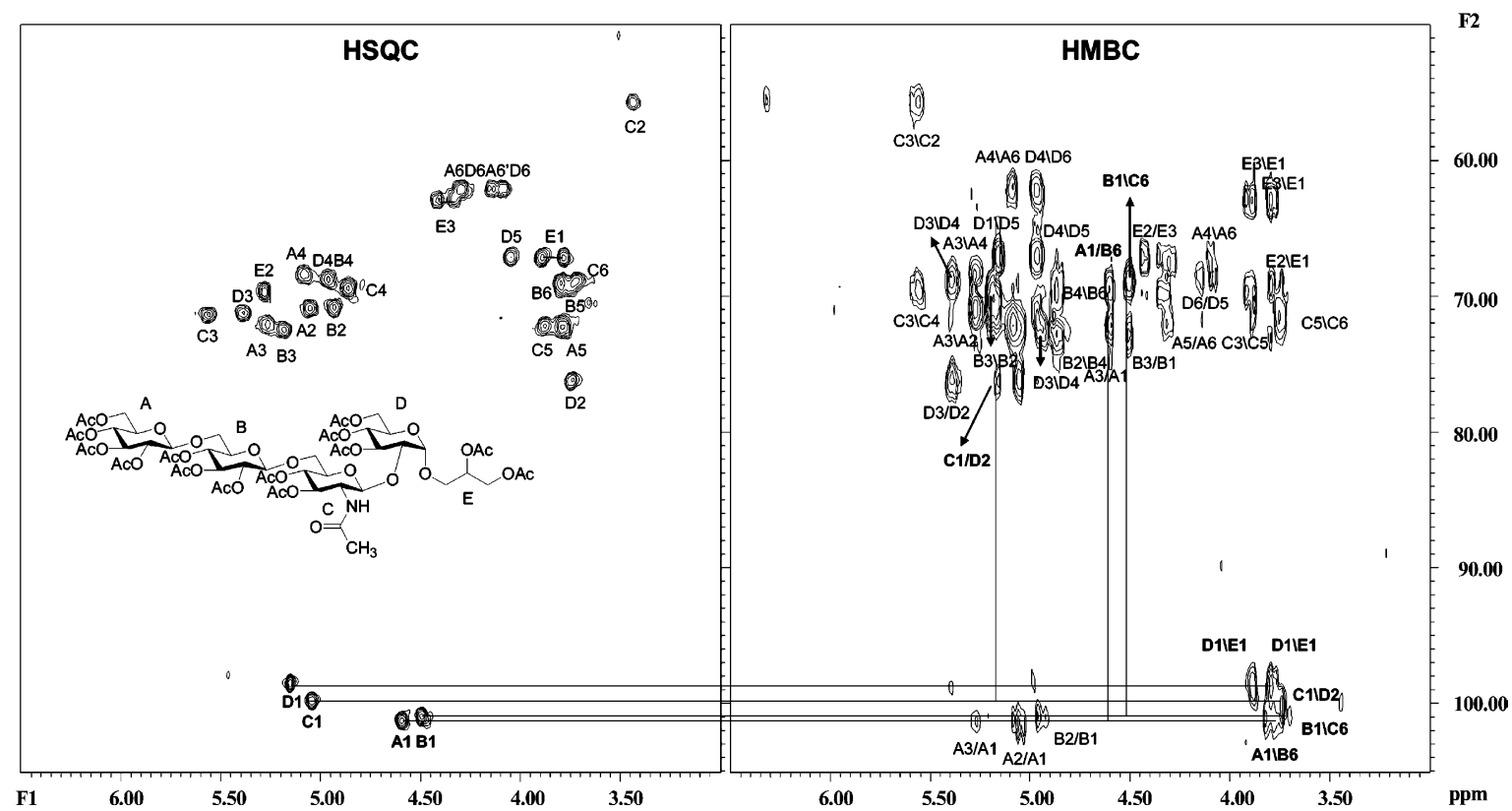

Figure 3. HMBC (right) in combination with HSQC (left) were used to assign the inter-residue linkages positions and sequences of the acetylated tetraglycosyl glycerol. The ${ }^{2} J$ and ${ }^{3} J$ correlations in the HMBC spectra are shown, from which the linkage analyses between residues could be assigned.

Glc $p$ (B) because of the correlation observed between $\mathrm{H}-$ 1 of Glcp (A) and C-6 of Glcp (B). Similar analysis established that Glc $p$ (B) was $1 \rightarrow 6$-linked to Glc $p$ NAc $(\mathrm{C})$, which was $\tilde{\beta}(1 \rightarrow 2)$-linked to Glc $p(\mathrm{D})$, which in turn was $\tilde{\alpha}(1 \rightarrow 1)$-linked to glycerol $(\mathrm{E})$. Thus, the carbohydrate moiety of the glycolipid from T. oshimai NTU-063 has the following structure: $\beta$-Glc $p-(1 \rightarrow 6)-\beta-G l c p-$ $(1 \rightarrow 6)-\beta$-Glc $p$-NAcyl- $(1 \rightarrow 2)-\alpha$-Glc $p$ - $(1 \rightarrow 1)$-glycerol. 
Table 3. Correlations observed in HMBC spectrum

\begin{tabular}{|c|c|c|c|c|}
\hline Residue & From proton & HMBC to carbons & ${ }^{3} J_{1,2}(\mathrm{~Hz})^{\mathrm{a}}$ & ${ }^{13} \mathrm{C}(\mathrm{ppm}){ }^{\mathrm{b}}$ \\
\hline$\beta-\operatorname{Glc} p(1 \rightarrow\}(\mathrm{A})$ & A1 & $\mathrm{B} 6, \mathrm{~A} 2, \mathrm{~A} 3$ & 7.8 & 101.4 \\
\hline 6)- $\beta$-Glc $p(1 \rightarrow\}$ (B) & B1 & $\mathrm{C} 6, \mathrm{~B} 2, \mathrm{~A} 3$ & 8.0 & 101.0 \\
\hline 6)- $\beta-\operatorname{Glc} p \mathrm{NAc}(1 \rightarrow\}(\mathrm{C})$ & $\mathrm{C} 1$ & D2 & 8.3 & 99.9 \\
\hline 2)- $\alpha-\operatorname{Glc} p(1 \rightarrow\}$ (D) & D1 & E1 & 4.1 & 98.6 \\
\hline \multirow[t]{2}{*}{$\mathrm{OCH}_{2} \mathrm{CH}(\mathrm{OAc}) \mathrm{CH}_{2} \mathrm{OAc}(\mathrm{E})$} & E1 & E2, E3 & - & - \\
\hline & $\mathrm{E} 2$ & $\mathrm{E} 1, \mathrm{E} 3$ & & \\
\hline
\end{tabular}

${ }^{a} \mathrm{H}_{-}{ }^{1} \mathrm{H}$ coupling constant between $\mathrm{H}-1$ and $\mathrm{H}-2$.

${ }^{b}{ }^{13} \mathrm{C}$ chemical shift of anomeric carbons.

Based on the structural information obtained from both fatty acid and carbohydrate moiety analyses, we determined the full structure of the major glycolipid from $T$. oshimai NTU-063 as $\beta$-Glc $p-(1 \rightarrow 6)-\beta-$ Glc $p$ - $(1 \rightarrow 6)-\beta$-Glc $p$-NAcyl- $(1 \rightarrow 2)-\alpha$-Glc $p$ - $(1 \rightarrow 1)$-glycerol diester, where the $N$-acyl group on 2-amino-2-deoxyglucopyranose is either $\mathrm{C}_{15: 0}$ or $\mathrm{C}_{17: 0}$ and $O$-acyl esters attached to the glycerol moiety are more heterogeneous and include straight, isobranched, and anteisobranched fatty acids (mainly from $\mathrm{C}_{15: 0}$ to $\mathrm{C}_{18: 0}$ ).

The glycolipid from T. oshimai NTU-063 has the same carbohydrate sequence and similar fatty acid composition in comparison to that of GL-1 from $T$. oshimai SPS-11. ${ }^{19}$ However, because neither linkage nor configuration was determined in the case of GL-1 we are not able to conclude if two have the same carbohydrate moiety. One minor difference between $T$. oshimai NTU-063 and T. oshimai SPS-11 is that the amide linked 3-hydroxy fatty acids in GL-1 are not found in this major glycolipid from $T$. oshimai NTU-063. It is noteworthy that the 3-hydroxy fatty acids in Thermus and Meiothermus ${ }^{20}$ are similar to those in the lipid A moiety. ${ }^{21}$ However, we have no evidence to suggest that the same biosynthetic pathway is involved, and the mechanism of glycolipid biosynthesis in neither Thermus nor Meiothermus has been fully investigated.

\section{Acknowledgements}

The work was supported in part by National Science Council, Taiwan. The NMR spectra were performed in High Speed Biomacromolecular NMR Core Facility supported by the National Research Program for Genomic Medicine. We are also grateful to Dr. Chi-Fon, Chang, Miss Ellen Yu, and Mr. Chun-I. Chen for technical assistance.

\section{References}

1. Pask-Hughes, R. A.; Shaw, N. J. Bacteriol. 1982, 149, 54 58.

2. Silva, Z.; Borges, N.; Martins, L. O.; Wait, R.; da Costa, M. S.; Santos, H. Extremophiles 1999, 3, 163-172.
3. Forterre, P.; Bouthier de la Tour, C.; Philippe, H.; Duguet, M. Trends Genet. 2000, 16, 152-154.

4. Lesley, S. A.; Kuhn, P.; Godzik, A.; Deacon, A. M.; Mathews, I.; Kreusch, A.; Spraggon, G.; Klock, H. E.; McMullan, D.; Shin, T.; Vincent, J.; Robb, A.; Brinen, L. S.; Miller, M. D.; McPhillips, T. M.; Miller, M. A.; Scheibe, D.; Canaves, J. M.; Guda, C.; Jaroszewski, L.; Selby, T. L.; Elsliger, M.-A.; Wooley, J.; Taylor, S. S.; Hodgson, K. O.; Wilson, I. A.; Schultz, P. G.; Stevens, R. C. Proc. Natl. Acad. Sci. U.S.A. 2002, 99, 11664 11669.

5. Huber, R.; Wilharm, T.; Huber, D.; Trincone, A.; Burggraf, S.; König, H.; Rachel, R.; Rockinger, I.; Fricke, H.; Stetter, K. O. Syst. Appl. Microbiol. 1992, 15, 340351 .

6. Langworthy, T. A.; Holzer, G.; Zeikus, J. G.; Tornabene, T. G. Syst. Appl. Microbiol. 1983, 4, 1-17.

7. De Rosa, M.; Gambacorta, A.; Huber, R.; Lanzotti, V.; Nicolaus, B.; Stetter, K. O.; Trincone, A. In Microbiology of Extreme Environments and its Potential for Biotechnology; da Costa, M. S., Duarte, J. C., Williams, R. A. D., Eds.; Elsevier: London, England, 1989; pp 167-173.

8. Wait, R.; Carreto, L.; Nobre, M. F.; Ferreira, A. F.; da Costa, M. S. J. Bacteriol. 1997, 179, 6154-6162.

9. Oshima, M.; Yamakawa, T. Biochemistry 1974, 13, 11401146.

10. Prado, A.; da Costa, M. S.; Madeira, V. M. C. J. Gen. Microbiol. 1988, 134, 1653-1660.

11. Donato, M. M.; Seleiro, E. A.; da Costa, M. S. Syst. Appl. Microbiol. 1990, 13, 234-239.

12. Chen, M. Y.; Lin, G. H.; Lin, Y. T.; Tsay, S. S. Int. J. Syst. Evol. Microbiol. 2002, 52, 1647-1654.

13. Williams, R. A. D.; da Costa, M. S. In Prokaryotes, 2nd ed.; Balows, A., Trueper, H. G., Eds., Springer: New York, 1992; 3745-3753.

14. Hakomori, S. J. Biochem. 1964, 55, 205-208.

15. Waeghe, T.; Darvill, A.; McNeil, M.; Albersheim, P. Carbohydr. Res. 1983, 123, 281-304.

16. Kelly, A. E.; Ou, H. D.; Withers, R.; Dotsch, V. J. Am. Chem. Soc. 2002, 124, 12013-12019.

17. Kogan, G.; Uhrin, D. In New Advances in Analytical Chemistry; Atta-ur-Rahman, Ed.; Harwood Academic: Amsterdam, 2000; pp 73-133.

18. Mulloy, B. Mol. Biotechnol. 1996, 6, 241-266.

19. Carreto, L.; Wait, R.; Nobre, M. F.; da Costa, M. S. J. Bacteriol. 1996, 178, 6479-6486.

20. Chung, A. P.; Rainey, F.; Nobre, M. F.; Burghardt, J.; da Costa, M. S. Int. J. Syst. Bacteriol. 1997, 47, 1225-1230.

21. Wilkinson, S. G.. In Ratledge, C., Wilkinson, S. G., Eds.; Gram-negative Bacteria; Academic: London, 1988; Vol. 1, pp 299-488. 